\title{
月五年二和 昭
}

ス祊の會つにの方思はメ最出室

力勘の會社て飞に法岕之千近席に

公繁選議は艮足しはる㤎1等

の加定に既間りてコを民素

南の注於巨會工戰1の間ア研

方東合て商施業後クに會儿究

海後は品て用獨

一薪凹民省は燃逸丙償にリに

帶琶間に早料澌にしル於

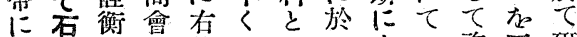

於油に䒬特毛して水滥資工研

浰俟に許二て發素渡力場究

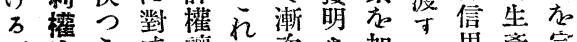

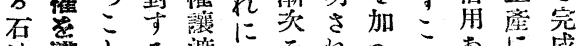

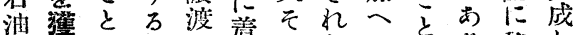

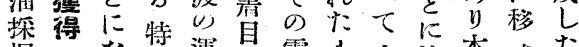

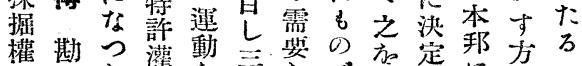

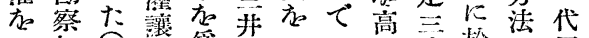

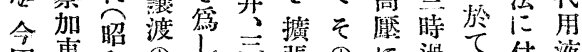

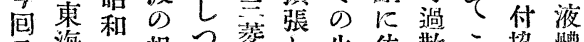

函海和根々落し生依散二協體

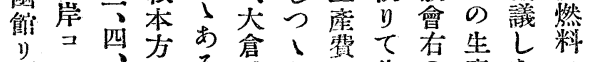

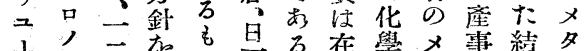

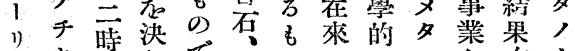

商キ事しで日0)のに二老有

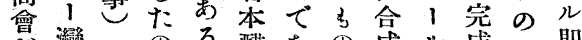

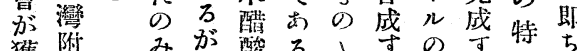

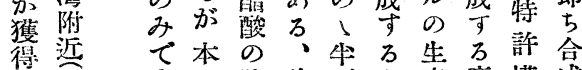

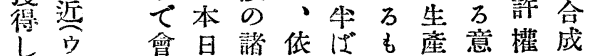

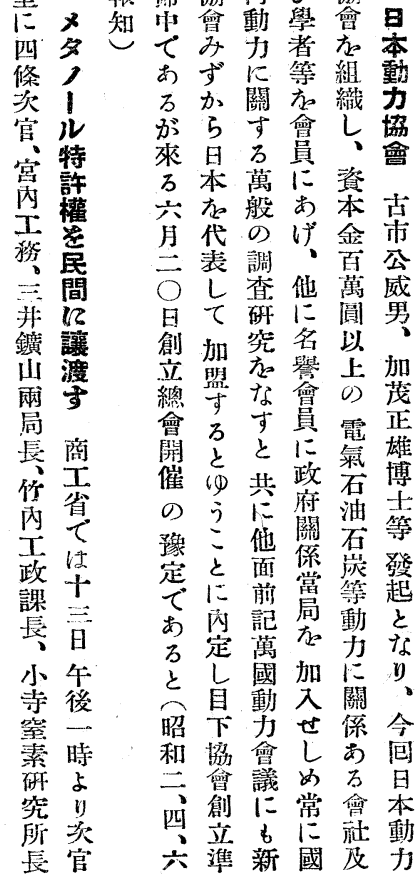

巳近田斜は及應學日田料

少し百た

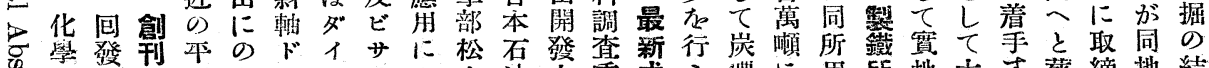

者行號野み1ナイよ上油上委式了傮に用所地大寸非締地結

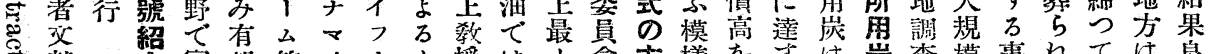

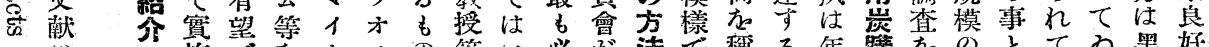

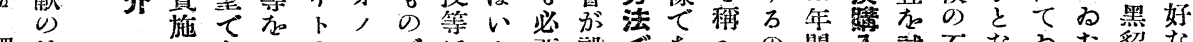

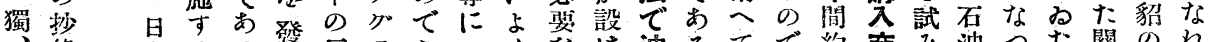

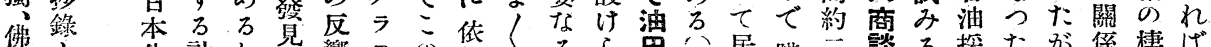

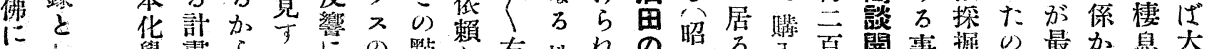

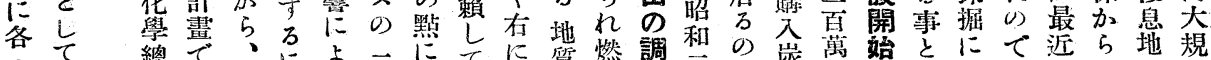

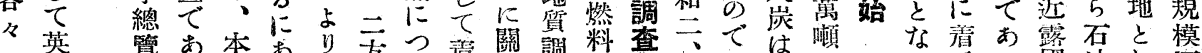

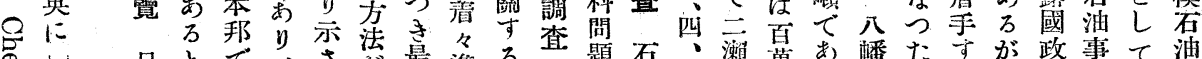

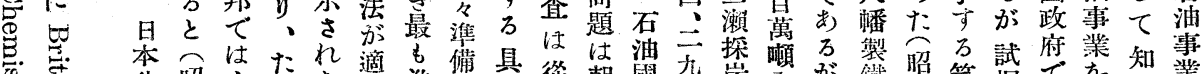

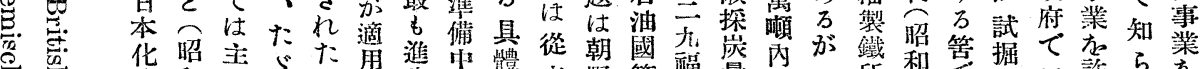

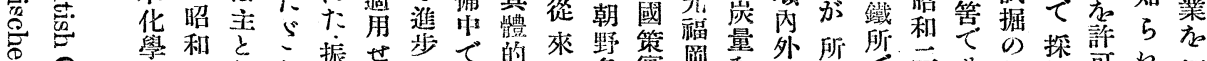

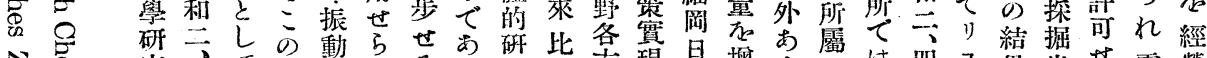

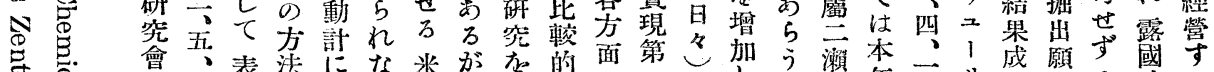

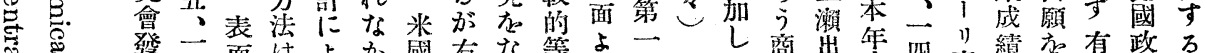

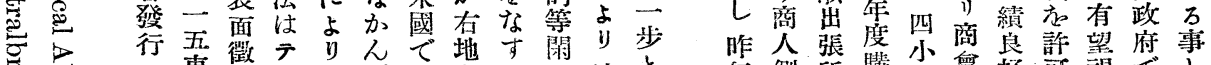

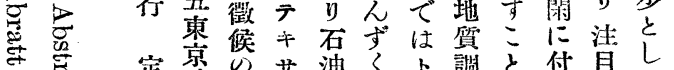

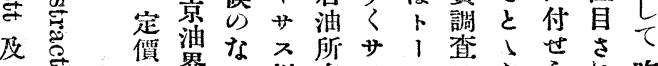

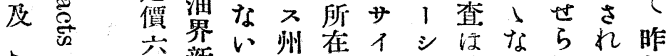

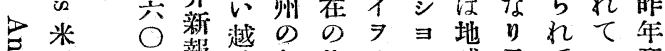

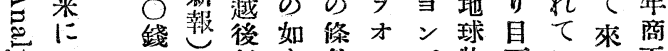
信き件, 公物卡いた要

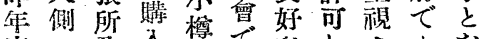

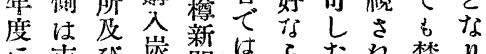
に市び宸留はらたれ禁り

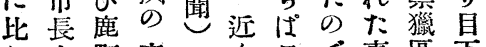

ᄂ上町商 購 申 9 談

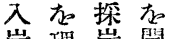
炭理宸阙 の 由 が始 減と約 L
しとが闇重だ試

雜

錄. 星で事區下

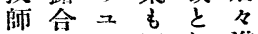
去辨。闇し隻 派聿》少て備 遣業氏万㒈中 
しし發のも三零の氏 万よ化本の裝食學得文献

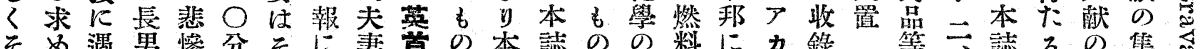

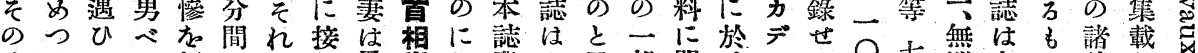

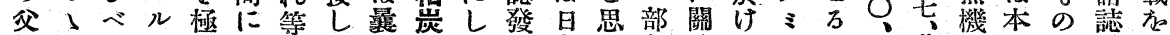

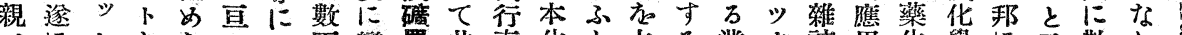

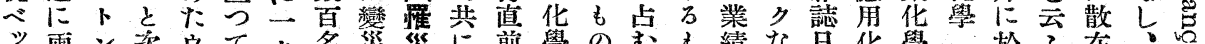

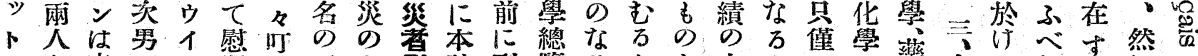

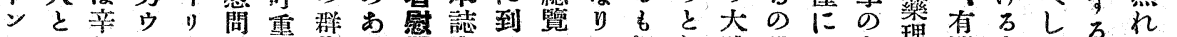
の房塖で

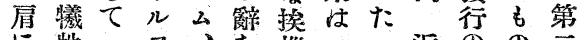

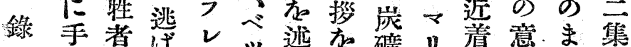

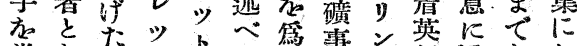

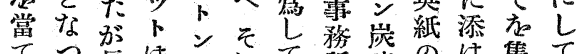
てつ長はとれて所硔の注集て

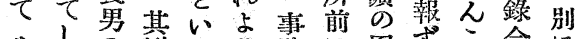

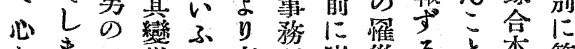

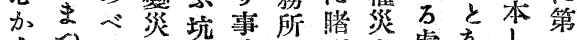
なたルの先務に列者に處施し焦

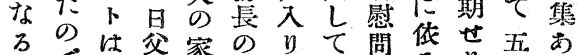

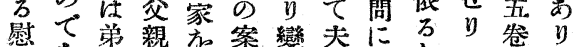

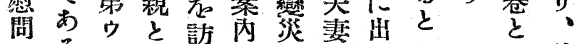

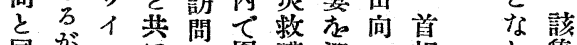
同がルにし留護迎心相し篹 情首フ作た焱團へたボては の相レ篻、坑のた命漸明

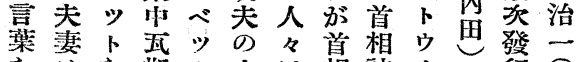

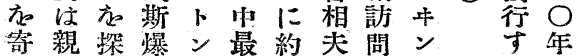
堨し體誹至理穖交 載ては公部中化缺 事は以きな毒學の 項 タてに万分等 に1之おは方 不ルれら其其八四載 足製去次基基鑛后

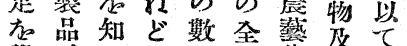
覺照乃 未の般稚岩其 ゆ朚に少虎學石の れ足創な網:化目 ぞ暖ろ創き羅肥學的本来

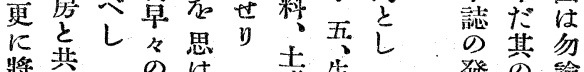
獎に のは变生發の論

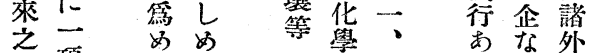

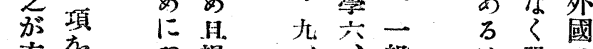
充袭揭分衛般は單に

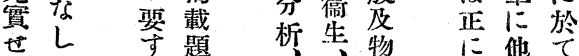

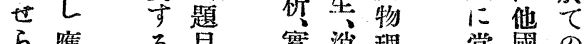
万用に等驗毒化皿の文

北商筑探地裳露くてつの員フブをせ

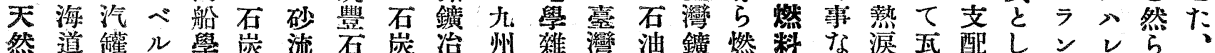

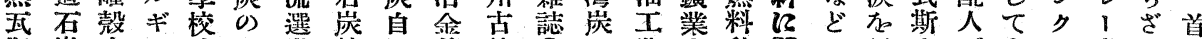
斯岸皮门校精岸鑛燃第然田業會動關は浮中て大八岸万相

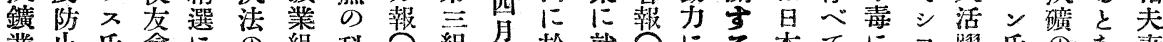

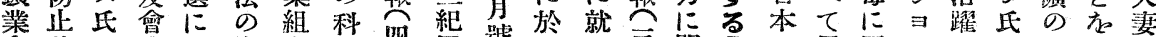

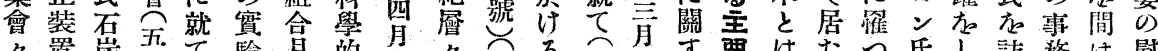

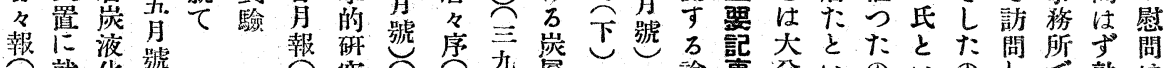

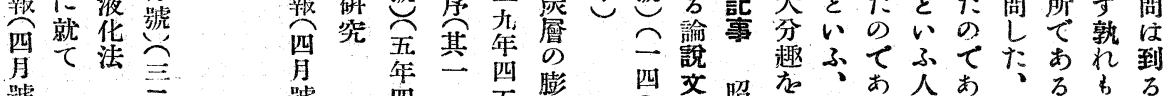

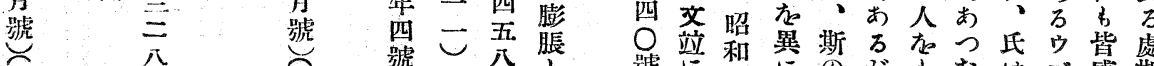

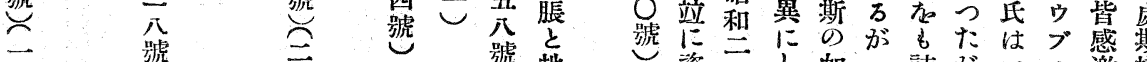

五 號

㙱

四

四

五

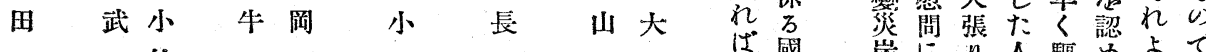

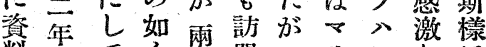
料四て 居問遂リとしに の月居首とし逐ン1た誠

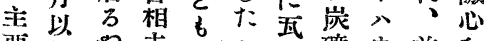

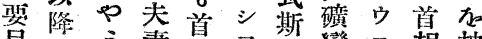

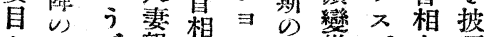

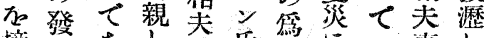
墑行山，妻氐病に山妻儿

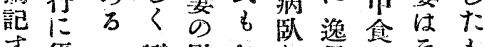

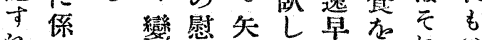

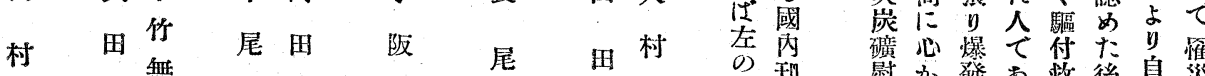

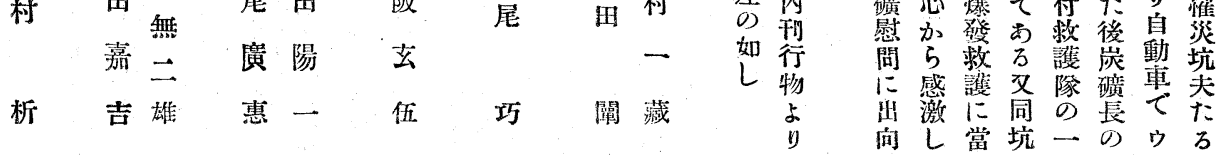




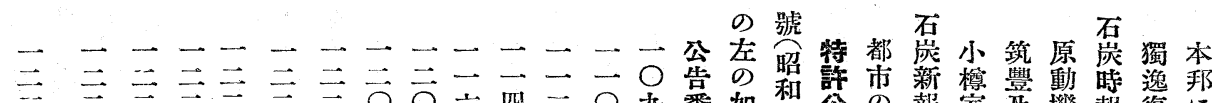

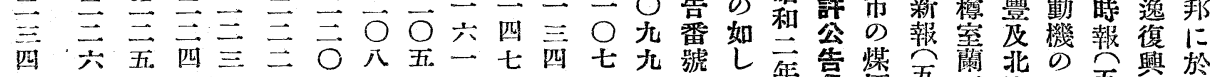

マタ破探汽燃汽加蒸重人瓦鑛給孷電高

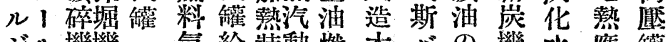
ジル機機氣給装動燃木バの譏水應罐 寻或 械

访

製其 於

造類 け

法似方

分 稚

工 物

化水置裝爟宸Ｉ精の素用

裝調置裝製ナ製改分潈

置整置漹１法良處水

於法 9 理裝

け調法置

$\begin{array}{ll}\text { 乃 } & \text { 整: } \\ \text { 給 } & \text { 裝 } \\ \text { 置 }\end{array}$

英 米伊米大莫東大獨英米米東東

國國國阪國京阪國國國國京京

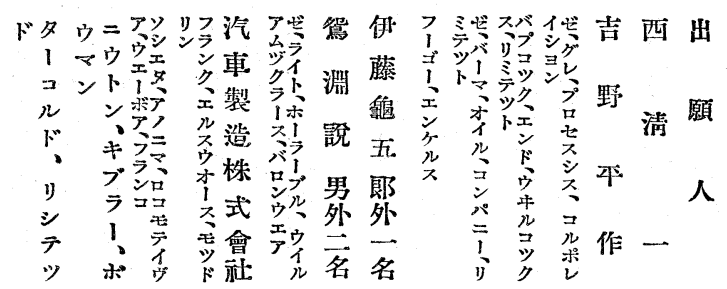

四叠煙五雨海進吾與け

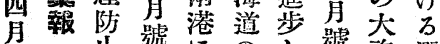

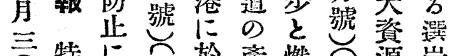

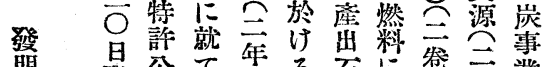

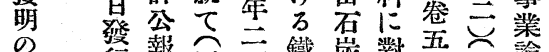

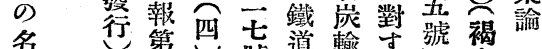

名

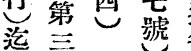

に

所號

载 炤

燃 和

整

動㽞

憅月

關筑

篮稳

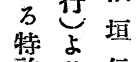

詐 y 信

出同太

公四郎
送 万

海 に III

陸 就求業

連て

絡の

改考

采案

畫:

概

要

加渡斯 黑北

賀邊渡井澤

山四忠 千

學 郎 郎 吉 堂
権:

錄:

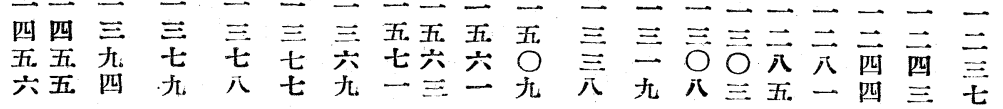

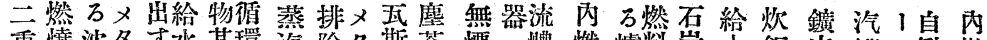
重燒沈夕寸水其環汽除夕斯芥㘹

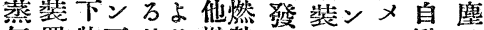
氣置物王禁 $y$ 燃熱生置瓦 1 働埃

鍋除斯置空料瓦機斯 夕宸燒

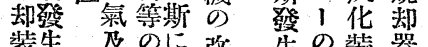

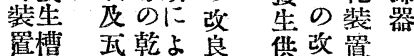

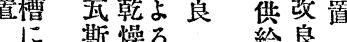

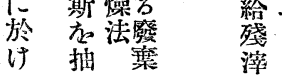

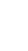

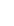

